\title{
Study of Obstetric Hysterectomy and Factors Contributing to It
}

\author{
Author \\ Dr Sudha Rani Panagar \\ Obstetrics and Gynaecology Department \\ SR hostel, CIMS MCH \& Hospital, Bilaspur, Chhattisgarh, Pin-495001
}

\begin{abstract}
A prospective study was done to estimate the incidence of obstetric hysterectomy at the hospital in relation to medical, social \& economic fields, its etiological factors or indications \& to study the maternal and fetal outcome of the procedure over two years was carried out. There are 12,658 confinements during study period from October 2012 to October 2015. 45 Emergency obstetric hysterectomies were done, incidence being 1:282 (0.36\%)birth. Mean age was 39.5 years. Majority (80\%) were from rural areas. Maximum cases were para 2-4. Most common indication for Emergency hysterectomy was uterine rupture (60\%) followed by Atonic PPH (17.78\%), Perforated uterus (8.89\%), morbidly adherent placenta (6.67\%), rupture ectopic pregnancy (2.22\%), burst abdomen (2.22\%). Majority uterine rupture cases were late referral from rural areas. Out of 27 cases of uterine rupture 8 cases with previous LSCS and 8 were obstructed labor. No maternal mortality was reported. Identification of high risk cases, early referral and procedures like internal artery ligation can reduce incidence of Emergency hysterectomy.
\end{abstract}

\section{INTRODUCTION}

Obstetric hysterectomy is one of the indicators of obstetric morbidity. It is considered dramatic operations in modern obstetric associated with great risk, where the uterus is removed at the time of caesarean section, following caesarean section immediately after vaginal delivery or in the period of puerperium in order to present maternal mortality and morbidity.

Emergency obstetric hysterectomy is a life saving surgical procedure in life threatening catastrophes of uterine rupture, morbidly adherent placenta, coagulopathy or uncontrollable haemorrhage. Many times all attempts to control haemorrhage fail and women's life is saved by compromising her reproductive capability by obstetric hysterectomy. ${ }^{1}$
Worldwide reports reveal striking difference among prevalence rate ranging from 1:361 to 1:3000 deliveries depending upon inherent characteristics of concerned obstetric population and standards of available maternity, family planning services and their utilization. ${ }^{2,3}$ Uterine rupture is a leading indication of emergency peripartum hysterectomy in third world countries accounting for $58 \%$ to $72 \%$ cases. $^{4,5}$ For the developed nations, picture is quite opposite and main indication $(50 \%)$ is abnormal placentation (praevia, accreta). ${ }^{6,7}$

In no other gynaecological or obstetrical surgery is the surgeon in as much a dilemma as when deciding to resort to an emergency hysterectomy. On one hand it is the last resort to save mother's life, and on the other hand, the mother's reproductive capability is to be sacrificed. Many a 
times it is a very difficult decision and requires very sound clinical judgement. Most of the times the condition of the patient is too critical to withstand the risks of anaesthesia or surgery. The maternal outcome greatly depends on timely decision, the surgical skill and the speed of performing obstetric hysterectomy. Planned obstetric hysterectomy can be performed in conditions like pregnancy associated with Carcinoma Cervix and invasive molar pregnancy. As the number of caesarean deliveries continue to rise, the number of pregnant patients with prior uterine incision is also increasing. The scar formed by the uterine incision exposes the gravid woman to increased morbidity such as uterine rupture, placenta praevia, placenta accreta and other complications. In turn, these conditions increase the risk of hysterectomy, blood transfusion and prolonged hospital stay. The incidence of obstetric hysterectomy varies from center to center depending upon available obstetric facilities like antenatal care, intranatal meticulous monitoring, trained paramedical personnel and obstetric performance at peripheral medical centres. ${ }^{8}$

This study was conducted in the Department of Obstetrics and Gynaecology at M.K.C.G. Medical Hospital, Berhampur, to analyse the various epidemiological, social and obstetric causes which have given rise to the relatively high incidence of obstetric hysterectomy in our institution. This is of importance because the patient undergoing this procedure are bad surgical and anaesthetic risks, and it is hoped this in depth analysis will throw light on some of the preventable aspects and will also assess the morbidity and mortality occurring from this procedure.

\section{MATERIAL AND METHODS}

The study will be undertaken in the Department of Obstetrics and Gynaecology, MKCG Medical College, Berhampur from October 2012 to October 2015. Forty five cases who had undergone obstetric hysterectomy were studied.

\section{Selection of patients-}

The patients will be related from Department of Obstetrics and Gynaecology, MKCG Medical College, Berhampur.

Inclusion criteria- Obstetric Factors like- PPH, Rupture uterus, Morbidly adherent Placenta, Septic Abortion, Perforation during voluntary termination of pregnancy, Puerperal sepsis.

Exclusion criteria- Hysterectomy done for gynaecological causes.

\section{METHOD}

A careful history of the patient regarding the obstetric status, gestational age, duration of labour pain, duration of ruptured membranes, history of manipulation by Traditional Birth Attendenrs or local doctor, etc., were obtained. Previous history of MTP, Myomectomy, caesarean section or any other operative manipulation was also taken.

A thorough clinical examination was carried out in each case with simultaneous resuscitation of the mother in cases of severe dehydration, haemorrhage or shock.

A broad spectrum antibiotics was started in every case. Blood grouping and Rh-typing was done in all cases and samples were collected for crossmatching. Obstetric examination was carried out per abdomen and by internal examination.

Either total or subtotal hysterectomy was performed depending on the condition of the patient. All cases were followed critically as regards to morbidity and mortality.

All patients on recruited will be subjected to proper history taking and pre, intra and postoperative observations. All the data at the end of the study will be recorded in a proforma analysed to make a proper conclusion.

\section{OBSERVATION}

The study entitled "OBSTETRIC HYSTERECTOMY AND FACTORS CONTRIBUTING TO IT" embodies the observation on 45 cases of obstetric hysterectomies performed in the Department of obstetrics \& Gynaecology, MKCG. Medical 


\section{JMSCR Vol||3||Issue||10||Page 7977-7984||October}

college, Berhampur during the period of October 2012 to October 2015. The observations follows: Majority of patients $(21,46.67 \%)$ were in age group 25-29 year, multipara were 34 (75.56.10\%), delivered at term (gestational age $37-40)$ were $36(90 \%)$. Thirty-four $(75.56 \%)$ were from low socio-economic status having monthly income $<5,000$ Rupees, $35 \quad(77.77 \%)$ were uneducated, 30 (66.67\%) were un-booked, and 36 $(80 \%)$ were from rural areas. Out of 45 patients, $32(71.11 \%)$ were referred cases. In 5 patients (14.29\%) delayed arrival to hospital was due to transport problems and reluctance of relatives to brought her to hospital.

Table-1: Socio-demographic characteristics of patients $(n=41)$

\begin{tabular}{|c|c|c|}
\hline & & \\
AGE IN YEARS & NO OF CASES & PERCENTAGE \\
\hline $20-24$ & 10 & 22.22 \\
\hline $25-29$ & 21 & 46.67 \\
\hline $30-34$ & 8 & 17.78 \\
\hline $35-39$ & 6 & 13.33 \\
\hline
\end{tabular}

\begin{tabular}{|c|c|c|}
\hline GRAVIDA & NO OF CASES & $\%$ \\
\hline 1 & 0 & 0.0 \\
\hline 2 & 22 & 48.89 \\
\hline 3 & 12 & 26.67 \\
\hline 4 & 7 & 15.55 \\
\hline$>\quad 5$ & 4 & 8.89 \\
\hline GESTATIONAL AGE & NO OF CASES & $\%$ \\
\hline PRETERM & 2 & 5 \\
\hline TERM & 36 & 90 \\
\hline POST-DELIVERY & 2 & 5 \\
\hline EDUCATION & NO OF CASES & $\%$ \\
\hline ILLITERATE & 35 & 77.77 \\
\hline \multirow[t]{2}{*}{ LITERATE } & 10 & 22.23 \\
\hline & NO OF CASES & $\%$ \\
\hline BOOKED & 15 & 33.33 \\
\hline UNBOOKED & 30 & 66.67 \\
\hline TOTAL & 45 & 100 \\
\hline $\begin{array}{l}\text { SOCIO-ECONOMIC } \\
\text { STATUS }\end{array}$ & NO OF CASES & $\%$ \\
\hline LOW & 34 & 75.56 \\
\hline MIDDLE & 11 & 24.44 \\
\hline HIGH & 0 & 0 \\
\hline TOTAL & 45 & 100.00 \\
\hline LOCALITY & NO OF CASES & $\%$ \\
\hline RURAL & 36 & 80 \\
\hline URBAN & 9 & 20 \\
\hline TOTAL & 45 & 100 \\
\hline
\end{tabular}

More than one risk factors predisposing to obstetric hysterectomy were identified in most of patients. The commonest risk factor was injudicious use of oxytocics and previous caesarean section (Table-2). 


\section{JMSCR Vol||3||Issue||10||Page 7977-7984||October}

Table-2: Risk factors predisposing to obstetric hysterectomy*

\begin{tabular}{|c|c|c|}
\hline SOCIAL FACTORS & NO. OF CASES & $\%$ \\
\hline \multicolumn{3}{|c|}{ Type of HCF availed prior to admission } \\
\hline District hospital & 8 & 25.00 \\
\hline Taluka hospital & 3 & 9.38 \\
\hline Community health center & 10 & 31.25 \\
\hline Primary health center & 8 & 25.00 \\
\hline Subcenter & 2 & 6.25 \\
\hline Nusing home \& clinics & 1 & 3.12 \\
\hline TOTAL & 32 & 100 \\
\hline \multicolumn{3}{|c|}{ Distance of nearest $\mathrm{HCF}$ (distance in $\mathrm{Km}$.) } \\
\hline$<25$ & 5 & 11.11 \\
\hline $25-60$ & 6 & 13.33 \\
\hline$>60$ & 34 & 75.56 \\
\hline TOTAL & 45 & 100 \\
\hline \multicolumn{3}{|l|}{ Type of communication } \\
\hline \multicolumn{3}{|l|}{ Vehicle } \\
\hline Ambulance & 37 & 82.22 \\
\hline Taxi & 2 & 4.44 \\
\hline Auto rickshaw & 4 & 8.88 \\
\hline Van/Jeep & 2 & 4.44 \\
\hline TOTAL & 45 & 100.00 \\
\hline
\end{tabular}

\begin{tabular}{|l|c|}
\hline Clinical factors & No. Of cases \\
\hline Previous CS & 8 \\
\hline Obstructed labour & 8 \\
\hline PPH & 8 \\
\hline Grand Multiparity & 11 \\
\hline Perforation of uterus & 4 \\
\hline Malpresentation & 4 \\
\hline Injudicious use of oxytocin & 2 \\
\hline
\end{tabular}

Table-3 shows, rupture uterus was the cause for obstetric hysterectomy in 27 (60\%) of cases.PPH, perforation of uterus and placental causes accounted for 8 (17.78\%), $4(8.89 \%)$ and $3(6.67 \%)$ cases respectively. Ectopic pregnancy, Gestational tumour and Burst abdomen were rarer causes accounting for one cause each.

Table-3: Indication for obstetric hysterectomy $(n=41)$

\begin{tabular}{|l|c|c|}
\hline Indications & No of cases & Percentage \\
\hline Rupture uterus & 27 & 60 \\
\hline PPH & 8 & 17.78 \\
\hline Perforation of uterus & 4 & 8.89 \\
\hline Placental causes(P.praevia, P. Acreta, P. Increta) & 3 & 6.67 \\
\hline Ectopic pregnancy & 1 & 2.22 \\
\hline Gestational Tumour & 1 & 2.22 \\
\hline Others (Burst Abdomen) & 1 & 2.22 \\
\hline
\end{tabular}




\section{JMSCR Vol||3||Issue||10||Page 7977-7984||October}

Table-4: Maternal Complications

\begin{tabular}{|l|c|c|}
\hline Intra-op complications & No. Of cases & $\%$ \\
\hline Shock & 5 & 11.11 \\
\hline Haemorrhage & 3 & 6.67 \\
\hline Bladder injury & 3 & 6.67 \\
\hline Broad lig. Haematoma & 3 & 6.67 \\
\hline Cardiac arrest & 1 & 2.22 \\
\hline Post-op complications & & \\
\hline Fever & 15 & 33.33 \\
\hline UTI & 10 & 22.22 \\
\hline Shock & 9 & 20.00 \\
\hline VVF & 1 & 2.22 \\
\hline Blood reaction & 1 & 2.22 \\
\hline Vomiting & 1 & 2.22 \\
\hline Decreased urination & 1 & 2.22 \\
\hline Chest infection & 1 & 2.22 \\
\hline
\end{tabular}

Table-4 shows, Intra-op complication noted in 15 cases (33.34\%) i.e. shock in 5 cases $(11.11 \%)$, haemorrhage, bladder injury and broad ligament haematoma in 3 cases $(6.67 \%)$ and cardiac arrest in one case. Post-op complications like fever, UTI, shock, VVF, blood reaction, vomiting, decreased urination and chest infection occurred in $33.33 \%, 22.22 \%, 20.22 \%, 2.22 \%, 2.22 \%, 2.22 \%$ respectively.

Table-5: Fetal Outcome $(\mathrm{N}=40)$

\begin{tabular}{|l|c|c|}
\hline Fetal outcome & No. Of cases & \% \\
\hline Fresh stillborn & 24 & 60 \\
\hline Preterm & 7 & 17.5 \\
\hline Satisfactory & 2 & 5.0 \\
\hline Small for gestational age & 1 & 2.5 \\
\hline Dead macerated & 6 & 15.0 \\
\hline Total & 40 & 100.0 \\
\hline
\end{tabular}

Table-5 shows, fresh still born in 24 cases $(60.0 \%)$ and satisfactory results in 2 cases $(5.0 \%)$.

Table-6: Association of foetal outcome with booking status

\begin{tabular}{|l|c|c|c|}
\hline Outcome & Booked & Unbooked & Total \\
\hline Alive & 7 & 3 & 10 \\
\hline Stillborn & 5 & 24 & 29 \\
\hline Total & 12 & 27 & 39 \\
\hline
\end{tabular}

Table- 6 shows, out of 29 perinatal deaths, 5 (17.24\%) were booked and $24(87.76 \%)$ were un-booked as shown by Table- 28 .

Table-7: Duration Of Hospital Stay

\begin{tabular}{|l|c|c|}
\hline Duration in days & No. Of cases & \% \\
\hline$<10$ & 6 & 13.33 \\
\hline $10-15$ & 32 & 71.11 \\
\hline $16-20$ & 5 & 11.11 \\
\hline$>20$ & 2 & 4.45 \\
\hline Total & 45 & 100.00 \\
\hline
\end{tabular}

Table-7 shows, the duration of hospital stay was less than 10 days in only 6 cases. Most of the patients remained in the hospital for 10-15 days. 


\section{Discussion}

Obstetrical hysterectomy has undergone tremendous change both in terms of indications and frequency of the procedure. It is mostly done for indications deemed to be serious and life threatening to the patient and not amenable to conservative management.

There are 12,658 deliveries from October 2012 to October 2015. Forty five obstetric hysterectomy operations were performed during the same period. Thus the incidence of obstetric hysterectomy was 1 per $282(0.36 \%)$ deliveries in this study.

The frequency of obstetric hysterectomy -

In our study In local studies In developed

Countries $^{9-14}$

$\begin{array}{ccc}1: 282 & 1: 139 & 1: 2224 \\ 1: 275 & 1: 4228 \\ 1: 331 & \\ 1: 361 & \end{array}$

The high incidence in our study is due to the reason that majority of the complicated referral cases were received in moribund state. Poor socioeconomic status, illiteracy, lack of proper referral system, unbooked status, non-availability of transport facilities, and mismanaged labour were similar contributing factors reported in other Pakistani studies. ${ }^{9,10,15}$

The highest frequency of the procedure in our study was-

among multipara in the 25-29 year age group,

In others studies-

it was highest in $>30$ year age group.

This is because of social trends of early marriage and emerging number of young patients with scarred uteri (12 out of 23 had scarred uterus). Most patients belonged to low

socioeconomic status having monthly income $<5,000$ rupees which is comparable with other local studies. ${ }^{1,3}$ Majority belonged to rural areas not having easy accessibility to a maternity and essential obstetric care. In urban setup, private clinics with inadequate and untrained staff were the main contributing factors causing grave morbidity as well as leading to maternal loss.

The education of girls has never been a priority in our culture and tradition. Majority of the

patients and their husbands were illiterate. Female education is a primary priority in developed countries as it has reduced severe obstetric complications due to improved health education. Most of patients were un-booked. Our results are comparable to results reported by other Pakistani studies as well as from other developing countries where lack of antenatal

care was identified as a major contributing factor for obstetric hysterectomy. ${ }^{9,11,12,16,17}$ Significant difference was observed when comparing booking status with

Incidence of complications of obstetric hysterectomy quoted in other Pakistani studies varies from 58 to $67 \% .^{8,18,19}$ Perinatal deaths in our study occurred in $63.41 \%$. In other studies it occurred in $42.8 \%$ to $78 \%$ cases. ${ }^{9,11,15}$ Most of the deaths were due to uterine rupture in un-booked patients who presented late in poor condition. Gould et al reported no perinatal deaths in patients with obstetric hysterectomy. ${ }^{13}$

Our results are comparable to results reported by other studies as well as from other developing countries where lack of antenatal care was identified as a major contributing factor for obstetric hysterectomy. Significant difference was observed when comparing booking status with locality.

\section{CONCLUSION}

While domiciliary midwifery is dying in the developed population of the world, in the traditional cultures of the developing countries like India, successful vaginal home delivery brings the women marital security, family status and esteem in her community.

A multipronged approach is needed for prevention of the unsafe motherhood by;

Improving the infrastructure for M.C.H. services in rural areas, 
Training programme for traditional birth attendant,

Timely referral to hospitals situated in areas where the M.MR is high so as to avoid delay in transporting patients in obstetric emergencies to district or teaching hospitals. (WHO 1986).

Rightly it is said, " you educate a man, you educate one person, you educate a women, you educate the whole family." There is urgent need to increase female literacy and raise the status of women.

Family planning and M.C.H are the two sides of the same coin. PPH, Rupture uterus and dangerous complications related to multiparity are common preventable problems. The craze for a son is responsible for many high parity births.

Obstetrics is an art and science combined, and its practitioners must be concerned simultaneously with the lives of at least two incricately connected patients- the mother and her foetus. Hence the obligations of the obstetricians is clear, the responsibility is enormous, but rewards of success are monumental.

In order to reduce the high incidence of obstetric hysterectomy with its attending complications and high mortality, all efforts should be directed towards removing ignorance, illiteracy and poverty. A declining trend in the rate of obstetric hysterectomy will be a sure indicator of our social and health development and will be extremely desirous

\section{BIBLIOGRAPHY -}

1. Najma Bano Shaikh, Shabnam Shaikh*, Jan Muhammad Shaikh.MORBIDITY AND MORTALITY ASSOCIATED WITH OBSTETRIC HYSTERECTOMY. J Ayub Med Coll Abbottabad 2010;22(2).

2. Najmi RS. Caesarean and postpartum hysterectomy - a study from lahore. J Coll Physicians Surg Pak 1994;4:120-5.

3. Gupta S, Hooker J, Beynon JL, Gibson JRM Obstetric Hysterectomy. J Obstet Gyneacol 1994;14:159-61.
4. Korejo R, Jafarey SN. Obstetric Hysterectomy: five years experience at Jinnah Postgraduate Medical Centre, Karachi. J Pak Med Assoc 1995;45:86-8.

5. . Onwudiegwu U, Okonofua FE. Emergency obstetric hysterectomy in a Nigerian hospital. J Obstet Gynecol 1995; 15:24-6.

6. Stanco LM, Schrimmer DB, Paul RH, Mishell DR. Emergency Peripartum hysterectomy and associated risk factors. Am J Obstet Gynecol 1993;168:879-83.

7. Baskett TF. Emergency obstetric hysterectomy. J Obstet Gynecol 2003;23:353-5.

8. . Rita Thaker, M.D., Rabia Khurshid, M.D., Abida Ahmad, M.D. Emergency Obstetric Hysterectomy: 10-year Review at SKIMS Srinagar, Kashmir. Journal of Medical Sciences 2012;15(2):149-52.

9. Najmi RS. Caesarean and postpartum hysterectomy - a study from lahore. J Coll Physicians Surg Pak 1994;4:120-5.

10. Korejo R, Jafarey SN. Obstetric Hysterectomy: five years experience at Jinnah Postgraduate Medical Centre, Karachi. J Pak Med Assoc 1995;45:86-8.

11. Begum I, Khan A, Khan S, Begum S. Caesarean and Postpartum hysterectomy. Pak J Med Res 2004;43:134-7.

12. Ehsan N, Mehmood A. Emergency peripartum hysterectomy: a

13. Gould DA, Butler-Manuel SA, Turner MJ, Carter PG. Emergency obstetric hysterectomy an increasing incidence. J Obstet Gynaecol 1999;19:580-3.

14. Zorlu CG, Turan C, Isik AZ, Danisman N, Mungan $\mathrm{T}$, Gokmen $\mathrm{O}$. Emergen hysterectomy in modern obstetric practice changing clinical perspective in time. Acta Obstet GynaecolScand 1998;77:186-90.

15. Shoaib F. Emergency Obstetric hysterectomy. J Coll Physicians Surg Pak 1996;6:319- 22. 
16. Onwudiegwu U, Okonofua FE. Emergency obstetric hysterectomy in a Nigerian hospital. J Obstet Gynecol 1995;15:24-6

17. Parveen S. Emergency Caesarean hysterectomy. J Surg Pak 2005;10(3):2730.

18. Noor S, Majid S, Ruby N. An audit of Obstetric hysterectomy.J Coll Physicians Surg, Pak 2001;11:642-5.

19. Tahir S, Aleem M, Akram S. Indication and maternal outcome of emergenc Peripartum hysterectomy. Pak J Med Science 2003;19:182-6. 